\title{
Efficacy and safety of parenteral omega 3 fatty acids in ventilated patients with acute lung injury
}

\author{
Ajay Gupta, Deepak Govil, Shaleen Bhatnagar, Sachin Gupta, Jyoti Goyal, Sweta Patel, \\ Himanshu Baweja
}

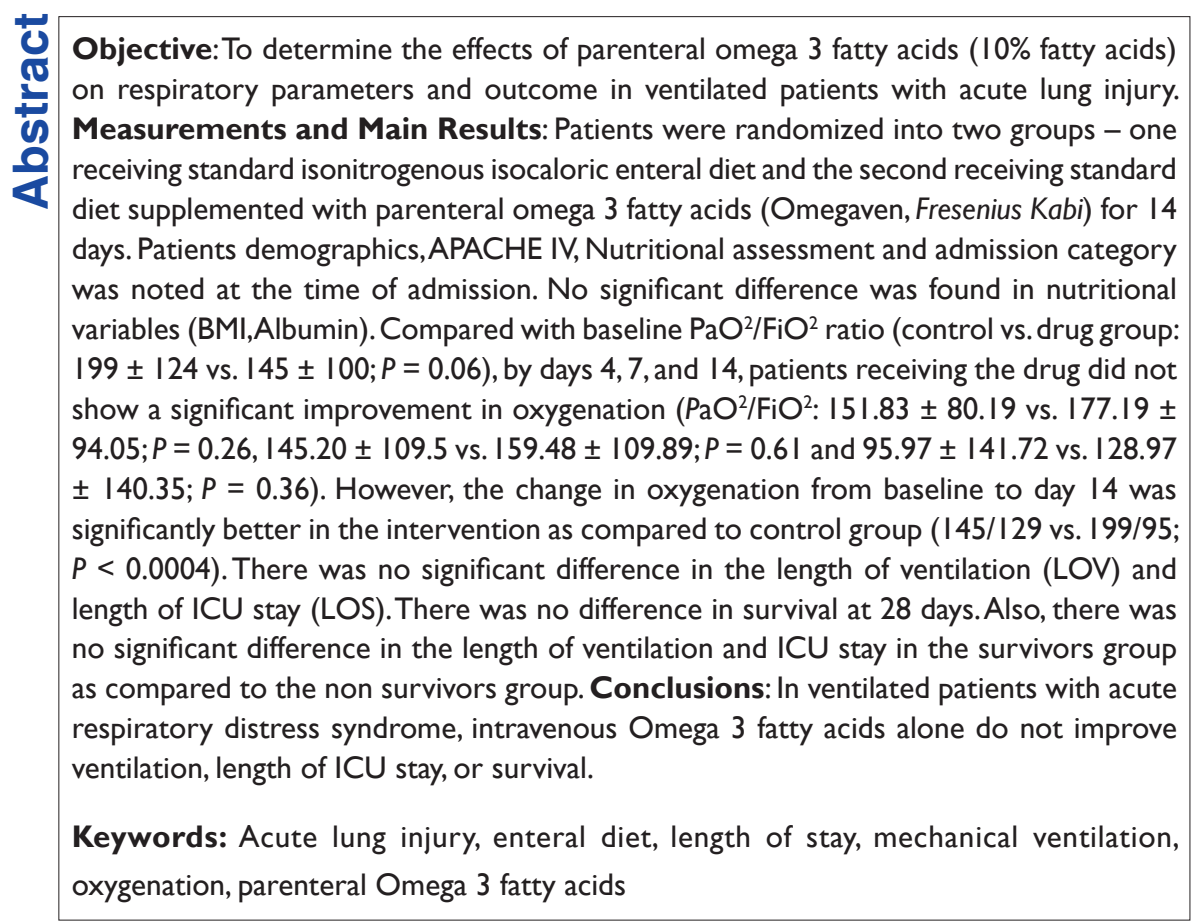

\begin{tabular}{|l|}
\hline Access this article online \\
\hline Website: www.ijccm.org \\
\hline DOI: 10.4103/0972-5229.83019 \\
\hline Quick Response Code: \\
\hline \\
\hline
\end{tabular}

\section{Introduction}

Advances in the ventilatory management of acute lung injury (ALI) and ARDS over the past decade have been dramatic. In particular, the use of a low-tidal volume $(6 \mathrm{~mL} / \mathrm{kg}$ predicted body weight) and plateau pressure-limited strategy has been demonstrated to reduce mortality from $40 \%$ to $31 \% .^{[1]}$ Further, a large, multicenter, randomized, controlled trial, ${ }^{[2]}$ demonstrated the equivalence of higher and lower levels

\section{From:}

Department of Intensive Care Medicine, Artemis Health Institute, Sector 51 Gurgaon, Haryana, India

\section{Correspondence:}

Dr. Ajay Gupta, Department of Intensive Care Medicine, 6A/47 Wea,

Karol Bagh, New Delhi - 110 005, India. E-mail: ajaygupta1967@ hotmail.com of positive end-expiratory pressure. Over this time, a number of nonventilatory therapies for ALI/ ARDS have been investigated. Many of these have not proven to be effective, while others appear more promising, lipids being one of them.

The lipid emulsions generally used in the parenteral nutrition of critically ill patients are rich in longchain triglycerides (LCT), especially linoleic acid (polyunsaturated series 6 fatty acid; PUFA n-6, 18:2 $\mathrm{n}-6)$. These fatty acids, aside from producing adverse metabolic effects (transitory hyperlipidemias), can alter pulmonary gas exchange due to their potentially proinflammatory properties. The MCT/LCT emulsions are oxidized faster and provide fewer amounts of PUFAs than LCT emulsions. Thus, MCT/LCT emulsions have 
been associated with a lower risk of lipid peroxidation and fewer alterations of membrane structures. ${ }^{[3]}$ Polyunsaturated fatty acids of the $n-3$ series (PUFA n-3) are precursors of biologically active substances, e.g., the series 3 and 5 eicosanoids. These molecules use the same metabolic routes and compete for the same elongases and desaturases as linoleic and arachidonic, but ultimately they are mediators that have a much less active biological profile than linoleic acid derivatives. ${ }^{[4]}$

In 146 patients with ARDS treated with an enteral diet rich in eicosapentaenoic acid, $\mathrm{y}$-linolenic, and antioxidants, an improved $\mathrm{PaO}_{2} / \mathrm{FiO}_{2}$ ratio, a reduction in pulmonary inflammatory response, frequency of new organ failures, days of mechanical ventilation and length of stay in ICU were observed..$^{[5]}$ In 100 patients with acute pulmonary injury receiving a similar enteral diet, oxygenation was better, pulmonary compliance improved, and there was less need for mechanical ventilation. ${ }^{[6]}$ The administration of lipid emulsions has been associated with changes in pulmonary function that depends on pulmonary disease, dose, duration, speed of administration, and kind of infused lipids. ${ }^{[7,8]}$ A metaanalysis of 12 randomized controlled trials comparing standard enteral nutrition with antioxidant nutrition found decreased rates of infection but again no effect on mortality. ${ }^{[9]}$

Many patients with ARDS require sedation/analgesia and muscle relaxation, inducing intestinal ileus and making intolerance to enteral nutrition. It has been hypothesized that adding n-3 to a MCT/LCT mixture used in enteral nutrition, should be beneficial because of the reduced amount of PUFA, would be less toxic than a lipid emulsion based on soybean oil, and that the addition of fish oil would be protective because of its antiinflammatory properties. ${ }^{[4]}$ A study which evaluated the hemodynamic changes and variations in pulmonary gas exchange that occurred in patients with ARDS given an intravenous lipid emulsion enriched with n-3 fatty acids could not show any benefit. ${ }^{[10]}$ In unselected critically ill medical patients, fish oil supplementation that increased the n-3/n-6 PUFA ratio to 1:2 did not affect inflammation or clinical outcome, compared to parenteral lipid nutrition with an MCT/LCT emulsion. ${ }^{[11]}$ A small study showed that while the LCT emulsion induced no deleterious effects on oxygenation in ARDS patients, the LCT/MCT emulsion improved the $\mathrm{PaO}_{2} / \mathrm{FiO}_{2}$ ratio and had a further beneficial effect on oxygen delivery ${ }^{[12]}$ The present study evaluated the effects of an intravenous lipid emulsion enriched with n-3 fatty acids in ventilated patients with acute lung injury.

\section{Materials and Methods}

This single-center, placebo-controlled, investigator blind, prospective, randomized clinical trial was approved by the institutional ethics committee. Written informed consent was obtained from all patients or their next of kin.

All patients admitted to the medical ICU of this hospital between July 1 and December 312009 were screened for eligibility. We studied 86 consecutive patients with suspected ARDS in the first 48 hours of admission. The inclusion criteria were: Bilateral pulmonary infiltrates of sudden onset in the chest radiograph, $\mathrm{PaO} 2 / \mathrm{FiO} 2$ less than 200, and pulmonary capillary pressure less than $18 \mathrm{~mm} \mathrm{Hg}{ }^{[13]}$ Patients were excluded for age younger than 18 or older than 80 years, pregnancy, liver failure (bilirubin > 3), HIV positivity, leukopenia $\left(<3500 \mathrm{~mm}^{3}\right)$, thrombocytopenia $\left(<100,000 \mathrm{~mm}^{3}\right)$, acute bleeding, severe renal insufficiency (creatinine $>2.5 \mathrm{mg} / \mathrm{dl}$ ) or need for renal dialysis, signs of heart failure, transplantation, multiple blood transfusions, participation in other clinical trials simultaneously or in the last 60 days, treatment with nitrous oxide or corticoids (prednisolone $2 \mathrm{mg} / \mathrm{kg} / \mathrm{d}$ or equivalent), multiple organ failure, severe dyslipidemia, propofol treatment, head injury, cerebral hemorrhage, receiving immunosuppressive regimen, radiation, allergy to any of the constituents of nutritional products.

Patients were divided into two groups:

Group 1: Standard diet (high fat, low carbohydrate kitchen feed)

Group 2: Standard diet + parenteral Omega 3 fatty acids, Omegaven ${ }^{\circledast}$ (Fresenius Kabi), an emulsion of $10 \%$ fish oil, for 14 days. This resulted in an n-3/n-6 ratio of 1:2 in the intervention group.

Patients in each stratum were assigned to the intervention or control group by the institutional intensivists, by use of a computer-generated block randomization list inaccessible to the investigators.

All participants were started on enteral feeding through a nasogastric tube within $24 \mathrm{hrs}$ of ICU admission. Enteral feeding was administered continuously, and the daily enteral intake was recorded. Conventional modes of ventilation were used in all cases, including assist control ventilation (pressure mode), pressure support ventilation (Evita 4, Drager, Lubeck, Germany). The main goals of mechanical ventilation were an oxygen saturation of $\geq 90 \%$, peak airway pressure of $\leq 35 \mathrm{~cm}$ $\mathrm{H}_{2} \mathrm{O}$, and tidal volume of $\leq 6 \mathrm{~mL} / \mathrm{kg}$. Levels of PEEP and $\mathrm{FIO}_{2}$ were adjusted to achieve these goals. Ventilation 
settings and decisions regarding readiness for extubation were left to the discretion of the investigators who were blinded to the nutritional prescription.

Following data were collected:

1. Demographic data: Age, sex, weight, height, body mass index (BMI), and diagnostic category for ICU admission (medical, surgical, trauma)

2. Assessment of oxygenation and respiratory function: ABG at baseline, 4, 7, and 14 days or discharge from ICU. Ventilatory settings, TV , PEEP were also recorded simultaneously

3. Assessment of metabolic and nutritional variables: Harris Benedict equation was used to calculate the predicted energy expenditure according to anthropometric variables. Albumin levels were assessed at baseline and on days 4, 7, and 14 .

Since the study medication was approved for therapeutic use, additional parameters of drug safety were not analyzed as outcome measures. As inhibition of platelet function is an established possible side effect of fish oil, the total quantity of transfused packed red cells/platelets, and bleeding events were recorded.

Primary outcome measures included changes in oxygenation and breathing patterns assessed at days 4 , 7 , and 14 .

Secondary outcomes included length of ventilation, length of ICU stay, length of hospital stay, and in hospital mortality.

Data will be presented as mean, standard deviation, median values, and mode as appropriate.

Demographic data were compared across with standard $t$ tests or one way analysis of variance for all continuous variables. All $P$ values were two sided, significance was assigned at a threshold of 0.05. A t test was used to compare a continuous variable (e.g., $\mathrm{PaO}_{2} /$ $\mathrm{FiO}_{2}$ ratio, length of stay). A contingency table (Fishers or chi-square test) was used to compare a categorical variable (e.g., survivor vs. nonsurvivors). Survival was evaluated with the Kaplan-Meir curve.

\section{Results}

Of the 86 patients screened, 61 were enrolled [Figure 1]. Of the remainder, 30 patients received the standard diet and 31 patients received the drug in addition to standard diet. Baseline data were not significantly different [Table 1]. $\mathrm{PaO}_{2} / \mathrm{FiO}_{2}$ ratio was better in the control group

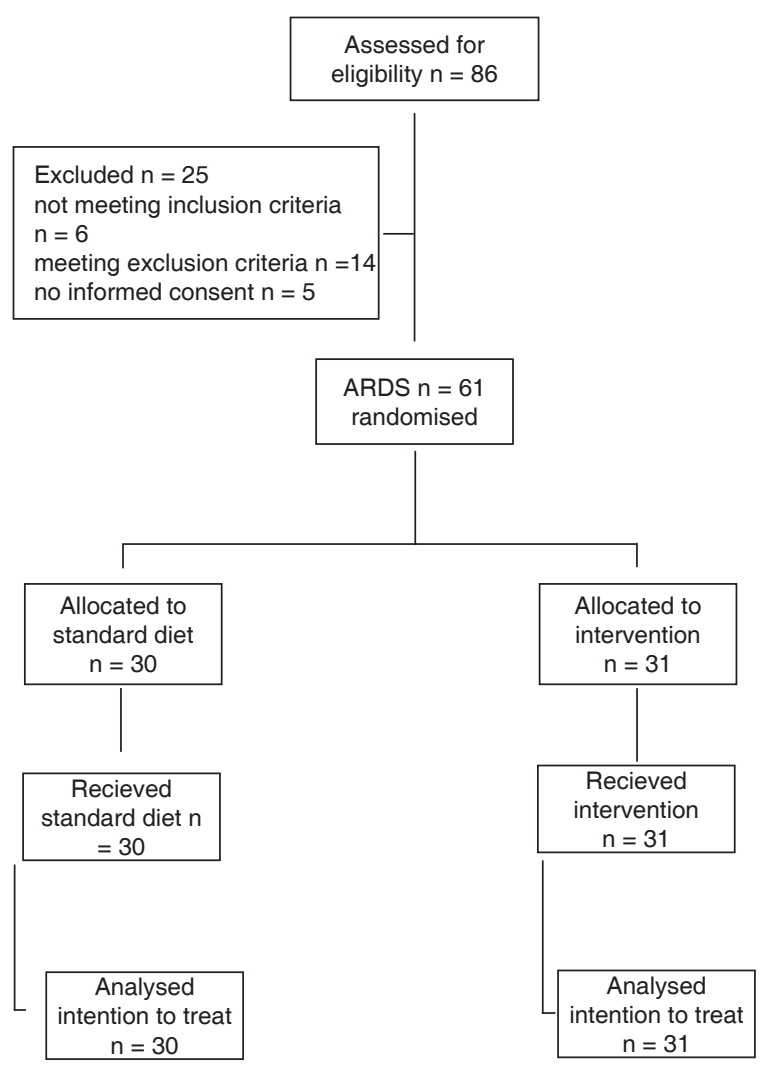

Figure I: Consort diagram showing conduct of the study

\begin{tabular}{|c|c|c|c|}
\hline & \multirow{2}{*}{$\frac{\text { Control }}{\text { Mean } \pm \text { SD }}$} & \multicolumn{2}{|c|}{ Drug } \\
\hline & & Mean \pm SD & $P$ value \\
\hline Age (yrs) & $46.63 \pm 16.44$ & $51.16 \pm 15.58$ & 0.27 \\
\hline $\operatorname{Sex}(N) M / F$ & $18 / 12$ & $19 / 12$ & 1.00 \\
\hline $\begin{array}{l}\text { Diagnostic category }(\mathrm{N}) \\
\text { Medical/Surgical }\end{array}$ & $28 / 2$ & $27 / 4$ & 0.67 \\
\hline APACHE IV score & $68.47 \pm 21.43$ & $64.06 \pm 21.55$ & 0.42 \\
\hline $\mathrm{PaO}_{2} / \mathrm{FiO}_{2}$ ratio & $199 \pm 124$ & $145 \pm 100$ & 0.06 \\
\hline $\mathrm{BMI} \mathrm{kg} / \mathrm{m}^{2}$ & $24.64 \pm 4.12$ & $27.07 \pm 7.48$ & 0.12 \\
\hline S. Albumin & $1.99 \pm .52$ & $2.22 \pm 0.56$ & 0.11 \\
\hline
\end{tabular}


to start with but still not significantly different from the drug group. BMI was nearly in the ideal range for both groups. Albumin levels were low at baseline and did not correlate with patient response over time, reinforcing the poor diagnostic and prognostic value of albumin in critical care illness.

\section{Outcome measures}

\section{Primary outcome measures}

Oxygenation shown in Table 2 was no different in the two groups at days 4,7 , or 14 . However, the observed fall in $\mathrm{PaO}_{2} / \mathrm{FiO}_{2}$ ratio in the control group from baseline to day 14 was significantly higher as compared to the drug group (199 to 95 vs. 145 to $128, P=0.0004$ ) [Figure 2].

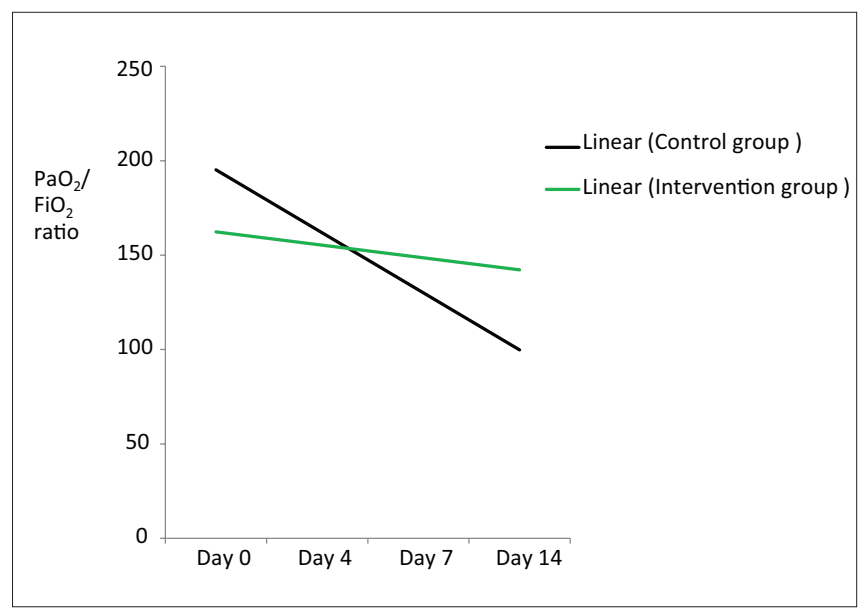

Figure 2: Trend line showing significant difference $(P<0.0004)$ in oxygenation $\left(\mathrm{P}_{\mathrm{a}} \mathrm{O}_{2} / \mathrm{FiO}_{2}\right.$ ratio) between the intervention and control group at day 14.

\section{Secondary outcome measures}

LOV and LOS, Table 3, was no different between the two groups.

Survivors were more in the drug group (24 vs. 17) at 28 days; Table 4 . At 28 days; LOV and LOS were same in the two groups, both for survivors and non survivors.

Overall survival was better in the drug group (22 vs. 16) Table 5. Length of hospital stay was shorter in the survivors group that received the drug compared to the survivors in the control group ( $21.5 \pm 13.49$ vs. $26.63 \pm$ 18.22) but not statistically significant $(P=0.32)$.

\section{Discussion}

In our opinion, this is the first study to examine the impact of parenteral Omega 3 fatty acids on ventilatory parameters and clinical outcome of ARDS patients who were otherwise fed enterally. Supplementation of enteral nutrition with fish oil for 14 days could not be proven to affect the examined ventilatory parameters or measures of clinical outcome in these patients. Only a significant increase in oxygenation could be shown at day 14 . The hypothesis had been that inflammatory and subsequent anti-inflammatory reactions would be reduced, ${ }^{[14,15]}$ resulting in clinical benefit. This expectation had been based on results of clinical studies. ${ }^{[16-19]}$ The majority of such studies showing a benefit from intravenous supplementation of fish oil had been performed in surgical patients.

\begin{tabular}{llll}
\hline Table 2: Gas exchange values $\left(\mathrm{PaO}_{2} / \mathrm{FiO}\right.$ & Ratio $)$ & & \\
\hline Day 4 & $151.83 \pm 80.19$ & $177.19 \pm 94.05$ & $P=0.26$ \\
Day 7 & $145.20 \pm 109.5$ & $159.48 \pm 109.89$ & $P=0.61$ \\
Day 14 & $95.97 \pm 141.72$ & $128.97 \pm 140.35$ & $P=0.36$ \\
\hline
\end{tabular}

\begin{tabular}{|c|c|c|c|}
\hline \multicolumn{4}{|c|}{ Length of ventilation (lov) days } \\
\hline Day I $(30 / 3 \mathrm{I})$ & $1.00 \pm 0.00$ & $1.00 \pm 0.00$ & $P=1.00$ \\
\hline Day $4(26 / 27)$ & $3.77 \pm 0.63$ & $3.8 \mathrm{I} \pm 0.54$ & $P=0.79$ \\
\hline Day $7(20 / 23)$ & $5.87 \pm 1.76$ & $6.10 \pm 1.62$ & $P=0.59$ \\
\hline Day I4 (8/I4) & $8.73 \pm 4.38$ & $10.13 \pm 4.42$ & $P=0.22$ \\
\hline Day $21(3 / 5)$ & $9.93 \pm 6.18$ & $12.26 \pm 6.73$ & $P=0.16$ \\
\hline Day $28(1 / 2)$ & $10.23 \pm 6.84$ & $13.06 \pm 8.04$ & $P=0.14$ \\
\hline \multicolumn{4}{|c|}{ Length of ICU stay (los) days } \\
\hline Day I $(30 / 3 \mathrm{I})$ & $1.0 \pm 0.00$ & $1.0 \pm 0.00$ & $P=1.00$ \\
\hline Day $4(26 / 27)$ & $3.77 \pm 0.63$ & $3.87 \pm 0.43$ & $P=0.44$ \\
\hline Day $7(20 / 23)$ & $6.03 \pm 1.69$ & $6.48 \pm 2.80$ & $P=0.38$ \\
\hline Day I4 (8/14) & $9.43 \pm 4.37$ & $10.48 \pm 4.34$ & $P=0.35$ \\
\hline
\end{tabular}




\begin{tabular}{lccc}
\hline Table 4: Outcome variables at 28 days & & & \\
\hline Survivors $(\mathrm{n})$ & 17 & 24 & $P=0.10$ \\
Length of ventilation & $11.75 \pm 6.47$ & $13.86 \pm 7.57$ & $P=0.37$ \\
Length of ICU stay & $15.88 \pm 8.61$ & $15.96 \pm 8.55$ & $P=0.97$ \\
Non survivors $(\mathrm{N})$ & 13 & 7 & $P=0.29$ \\
Length of ventilation & $10.7| \pm| 4.55$ & $11.78 \pm 10.63$ & $P=0.85$ \\
Length of ICU stay & $10.86 \pm 14.59$ & $12.89 \pm 12.63$ & $P=0.73$ \\
\hline
\end{tabular}

\begin{tabular}{lccc}
\hline \multicolumn{1}{l}{ Table 5: Outcome variables for hospital stay } & & \\
\hline Survivors $(\mathrm{n})$ & 16 & 22 & $P=0.19$ \\
Length of hospital stay (days) & $26.63 \pm 18.22$ & $21.5 \pm 13.49$ & $P=0.32$ \\
Non survivors (N) & 14 & 9 & $P=0.19$ \\
Length of hospital stay (days) & $10.93 \pm \mid 4.62$ & $12.89 \pm 12.63$ & $P=0.74$ \\
\hline
\end{tabular}

There may be several reasons why the expected effects of fish oil supplementation could not be demonstrated in this study. First, control patients were more severely ill in terms of $\mathrm{PaO}_{2} / \mathrm{FiO}_{2}$ ratio though the APACHE scoring was comparable. Second, the choice of lipids for standard care could partially explain why fish oil supplementation was not efficacious. In most clinical studies showing a benefit for fish oil, pure LCT lipids had been used in the control groups. LCT lipids, however, have been demonstrated to exert inflammatory and immunosuppressive influence on septic patients. ${ }^{[20]}$ Parenteral Omega 3 fatty acids have been shown to improve glucose control and decrease inflammatory markers in COAD and after major surgery patients. ${ }^{[21,22]}$ In the present study, standard diet containing 50\% MCT and $50 \%$ LCT was used, which reduced the average daily dose of linoleic acid to less than $0.3 \mathrm{~g} / \mathrm{kg}$. Thus, the expected effects of modifying the LCT/MCT ratio may not have been detected because the standard nutrition itself had fewer immunological side effects. Third, the route of use and specific composition of n-3 PUFAs could be important for their immunomodulatory effect. Enteral application of a mixture of fish oil, canola and borage oil, which - in contrast to fish oil alone - contains a substantial amount of gamma-linolenic acid, has shown to improve outcome parameters in acute lung injury ${ }^{[6]}$ and acute respiratory distress syndrome. ${ }^{[5]}$ It may also be that this PUFA composition and its enteral application carry more benefit than the parenteral application of fish oil.

\section{Adverse events}

Considering their mechanism of action, one could logically expect two principal side effects of n-3-PUFAs: Impaired hemostasis (due to reduced synthesis of thromboxane) and reduced immune function. Bleeding events did not occur more frequently in the intervention group. The anti-inflammatory potential of fish oil may be harmful. No influence of fish oil supplementation on nutritional status, as assessed by weight and albumin (data not shown), was observed. In effect, the present study produced no evidence that fish oil supplementation is harmful for the critically ill.

\section{Limitations}

Some limitations of the present study merit consideration. Sample-size estimates were based on data from a previous study in a less heterogeneous population. To compensate for greater variability, much larger sample sizes could well have been necessary to detect an effect of fish oil supplementation. The dose of fish oil may have been insufficient to produce an immunomodulatory effect. However, the intervention in this study was aimed at altering the n-3/n-6 PUFA ratio to $1: 2$. This aim was generally achieved with a daily fish oil dose of $0.1 \mathrm{~g} / \mathrm{kg}$. Favorable effect of fish oil have been demonstrated with daily doses as low as $0.1-0.2$ $\mathrm{g} / \mathrm{kg}(17)$.

\section{Conclusions}

In comparison to standard enteral nutrition, supplementation with parenteral fish oil did not change parameters of ventilation or clinical outcome in selected ARDS patients.

\section{References}

1. Ventilation with lower tidal volumes as compared with traditional tidal volumes for acute lung injury and the acute respiratory distress syndrome. N Engl J Med 2000;342:1301-8.

2. Brower RG, Lanken PN, MacIntyre N, Matthay MA, Morris A, Ancukiewicz M, et al. Higher versus lower positive end-expiratory pressures in patients with the acute respiratory distress syndrome. N Engl J Med 2004;351:327-36.

3. Halliwell B, Chiricos S. Lipid peroxidation: Its mechanism, measurement and significance. Am J Clin Nutr 1993;57(5 Suppl):715S-24S.

4. Calder PC. Long-chain n-3 fatty acids and inflammation: Potential application in surgical and trauma patients. Braz J Med Biol Res 2003;36:433-46.

5. Gadek JE, DeMichele SJ, Karlstad MD, Pacht ER, Donahoe M, Albertson TE, et al. Effect of enteral feeding with eicosapentaenoic 
acid, gamma-linolenic acid, and antioxidants in patients with acute respiratory distress syndrome: Enteral Nutrition in ARDS Study Group. Crit Care Med 1999;27:1409-20.

6. Singer P, Theilla M, Fisher H, Gibstein L, Grozovski E, Cohen J. Benefit of an enteral diet enriched with eicosapentaenoic acid and gamma-linolenic in ventilated patients with acute lung injury. Crit Care Med 2006;34:1033-8.

7. Mathru M, Dries DJ, Zecea A, Fareed J, Rooney MW, Rao TL. Effect of fast vs slow intralipid infusion on gas exchange, pulmonary hemodynamics, and prostaglandin metabolism. Chest 1991;99:426-9.

8. Hwang TL, Huang SL, Chen MF. Effects of intravenous fat emulsion on respiratory failure. Chest 1990;97:934-8.

9. Beale RJ, Bryg DJ, Bihari DJ. Immunonutrition in the critically ill: A systematic review of clinical outcome. Crit Care Med 1999;27:2799-805.

10. Sabater J, Masclans JR, Sacanell J, Chacon P, Sabin P, Planas M. Effects on hemodynamics and gas exchange of omega-3 fatty acidenriched lipid emulsion in acute respiratory distress syndrome (ARDS): A prospective, randomized, double-blind, parallel group study. Lipids Health Dis 2008;7:39.

11. Friesecke S, Lotze C, Köhler J, Heinrich A, Felix SB, Abel P. Fish oil supplementation in the parenteral nutrition of critically ill medical patients: A randomized controlled trial. Intensive Care Medicine 2008;34:1411-20.

12. Faucher M, Bregeon F, Gainnier M, Thirion X, Auffray JP, Papazian L. Cardiopulmonary effects of Lipid Emulsions in Patients with ARDS. Chest 2003;124:285-91.

13. Bernard GR, Artigas A, Brigham KL, Carlet J, Falke K, Hudson $\mathrm{L}$, et al. The American-European Consensus Conference on ARDS: Definitions, mechanisms, relevant outcomes, and clinical trial coordination. Am J Respir Crit Care Med 1994;149:818-24.

14. Wendel M, Paul R, Heller AR. Lipoproteins in inflammation and sepsis. II: Clinical aspects. Intensive Care Med 2007;33:25-35.

15. Mayer K, Schaefer MB, Seeger W. Fish oil in the critically ill: From experimental to clinical data. Curr Opin Clin Nutr Metab Care 2006;9:140-8.

16. Wichmann MW, Thul P, Czarnetzki HD, Morlion B.J, Kemen M, Jauch KW. Evaluation of clinical safety and beneficial effects of fish oi containing lipid emulsion (Lipoplus, MLF541): Data from a prospective, randomized, multicenter trial. Crit Care Med 2007;35:700-6.

17. Heller AR, Rossler S, Litz RJ, Stehr SN, Heller SC, Koch R, et al. Omega-3 fatty acids improve the diagnosis-related clinical outcome. Crit Care Med 2006;34:972-9.

18. Berger MM, Chiolero RL, Tappy L, Revelly JP, Geppert J, Franke C, et al. Safety of fish oil containing parenteral nutrition after abdominal aorta aneurysm surgery. Intensive Care Med 2005;31:S32.

19. Tsekos E, Reuter C, Stehle P, Boeden G. Perioperative administration of parenteral fish oil supplements in a routine clinical setting improves patient outcome after major abdominal surgery. Clin Nutr 2004;23: 325-30.

20. Mayer K, Fegbeutel C, Hattar K, Sibelius U, Kramer HJ, Heuer KU, et al. Omega-3 vs. omega-6 lipid emulsions exert differential influence on neutrophils in septic shock patients: Impact on plasma fatty acids and lipid mediator generation. Intensive Care Med 2003;29:1472-81.

21. Matsuyama W, Mitsuyama H, Watanabe M, Oonakahara K, Higashimoto I, Osame M, et al. Effects of Omega - 3 polyunsaturated fatty acids in COAD. Chest 2005;128:3817-27.

22. Wendel M, Impact of TPN including omega 3 fatty acids after major surgery. e-SPEN 2007;2:e103-1

How to cite this article: Gupta A, Govil D, Bhatnagar S, Gupta S, Goyal J, Patel S, Baweja H. Efficacy and safety of parenteral omega 3 fatty acids in ventilated patients with acute lung injury. Indian J Crit Care Med 2011;15:108-13.

Source of Support: Nil, Conflict of Interest: None declared.

\section{Staying in touch with the journal}

1) Table of Contents (TOC) email alert Receive an email alert containing the TOC when a new complete issue of the journal is made available online. To register for TOC alerts go to www.ijccm.org/signup.asp.

\section{2) RSS feeds}

Really Simple Syndication (RSS) helps you to get alerts on new publication right on your desktop without going to the journal's website. You need a software (e.g. RSSReader, Feed Demon, FeedReader, My Yahoo!, NewsGator and NewzCrawler) to get advantage of this tool. RSS feeds can also be read through FireFox or Microsoft Outlook 2007. Once any of these small (and mostly free) software is installed, add www.ijccm.org/rssfeed.asp as one of the feeds. 